\title{
HOSPITALIDADE E ENRAIZAMENTO EXISTENCIAL: AS DIFICULDADES FILOSÓFICAS DE UM CONCEITO
}

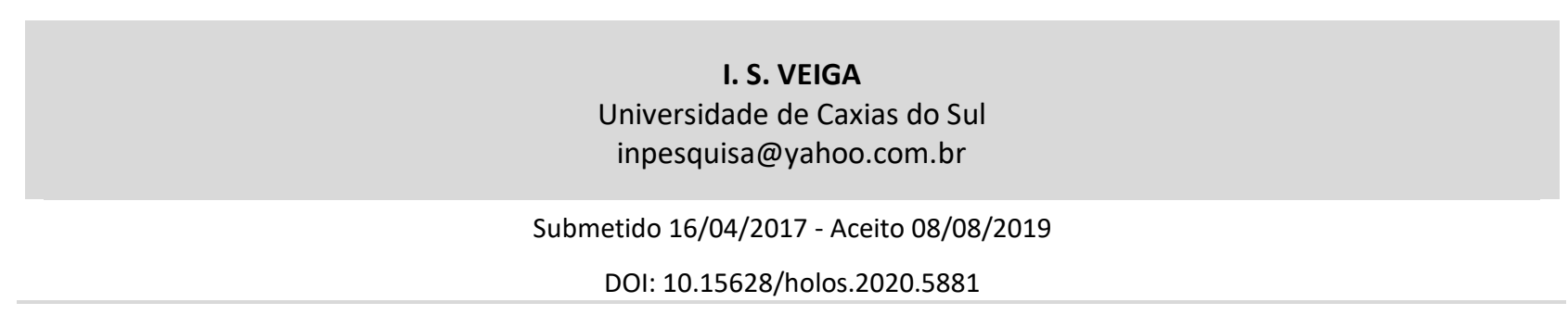

\section{RESUMO}

Este artigo trata sobre a hospitalidade e a dificuldade em elaborar o seu conceito, principalmente para uma análise teórica. Na primeira parte, são mostrados os motivos desta dificuldade, os quais remetem a uma diversidade e ambiguidade da expressão. Na segunda parte, a inserção de parâmetros filosóficos permite um estudo

aprofundado do processo conceitual e fornece uma alternativa de solução. O resultado alcançado mostra que a hospitalidade faz parte das realizações humanas e deve ser conceituada de forma diferente da tradicional, ou seja, a partir de um recurso metodológico proveniente da filosofia heideggeriana: os indícios formais.

PALAVRAS-CHAVE: hospitalidade; conceito; processo conceitual; indícios-formais.

\section{HOSPITALITY AND EXISTENTIAL ROOTING: THE PHILOSOPHICAL DIFFICULTIES OF A CONCEPT}

\begin{abstract}
This article deals with the hospitality and the difficulty in elaborating its concept, mainly for a theoretical analysis. In the first part are shown the reasons for this difficulty, which refer to a diversity and ambiguity of expression. In the second part, the insertion of philosophical parameters allows an in-depth study of the conceptual process and
\end{abstract}

provides an alternative solution. The result achieved shows that hospitality is part of the human achievements and must be conceptualized in a different way from the traditional, i. e., from a methodological resource derived from the heideggerian philosophy: the formal indication. 


\section{INTRODUÇÃO}

A expressão "hospitalidade" é complexa. Os seus diferentes significados possuem elementos teóricos, abstratos e, inclusive, outros tantos que remetem a aplicações no mundo concreto. Diante disso, instaura-se a complexidade e, esta se mostra na impossibilidade de se trabalhar com o conceito de hospitalidade de uma forma unívoca. Desse modo, é possível afirmar, simplesmente, que não sabemos o que significa "hospitalidade". Não sabemos se ela é uma categoria antropológica, cultural ou apenas uma consideração científico-mercadológica. A dificuldade serve como um ponto de partida para um questionamento mais profundo e, justifica nos determos no processo conceitual como um todo, principalmente aquele realizado na área de filosofia. Portanto, o ponto de partida, deste artigo, questiona o conceito de hospitalidade e, por decorrência, questiona também o processo conceitual, desenvolvendo uma crítica do uso de conceitos na filosofia em geral.

O conceito de hospitalidade cumpre um papel semelhante a outros que são também passíveis de diferentes compreensões e alvo de controvérsias. Este é um aspecto que justifica a necessidade de situarmos um ponto específico para esta investigação. Por isso, selecionamos a seguinte pergunta; como é possível conceitualizar a hospitalidade? Esta forma ampla deve ser delimitada pela seguinte via negativa: qual é a causa da falta de solidez do que seja aquilo que compreendemos como "hospitalidade"? Finalmente, esta delimitação explora uma equivalência entre "falta de solidez" e "dificuldade de conceituar a hospitalidade", exigindo que se prove ou se argumente que tal equivalência é mesmo possível. O background desse movimento delimitador é a constatação de que não sabemos o que significa a hospitalidade, ou melhor, não sabemos o que significa, mais precisamente, o "conceito" de hospitalidade.

A nossa hipótese principal é que a causa, da dificuldade de conceituar a hospitalidade, deriva das diferentes posturas ou atitudes humanas. Assim, a hospitalidade enquanto conceito contém uma recepção peculiar, constituída dos diferentes aspectos da existência humana. Esta diversidade constitui uma base "originária" a partir da qual emerge um "relativismo cultural" no qual "flutua" as diferentes significações de "hospitalidade". Não obstante, o uso do termo hospitalidade possua esta condição diversificada, com aspectos apontados para elementos diretos da realidade, o foco aqui é tentar concebê-la como um conceito filosófico. E, este difícil intuito abriria a investigação para uma abordagem sobre o processo conceitual em geral, mais especificadamente na própria filosofia. Esta abertura não é um procedimento fácil, nem inocente, mas complexo e prenhe de consequências à prática da filosofia. Neste sentido, o mérito do tema da "hospitalidade" é oferecer esta dificuldade de definição como um estimulo da discussão. E, com isso, permitir que a filosofia revisite os seus próprios métodos e procedimentos. Isto será feito em dois momentos

Nas duas seções abaixo, trataremos o seguinte: primeiro, justificamos que existem dificuldades na conceitualização da hospitalidade a partir de âmbitos diversos, tentando identificar suas causas. Em segundo lugar, investigamos um contraponto entre duas direções diferentes do processo conceitual: o modo mais tradicional e um modo heterodoxo, ambos concebem os 
conceitos filosóficos de formas diferentes. Para desenvolver essa seção, buscaremos suporte na filosofia de Heidegger e na sua proposta de tematizar a existência a partir dos indícios-formais. ${ }^{1}$

\section{AS DIFICULDADES CONCEITUAIS E A SELEÇÃO DE UMA VIA DE ANÁLISE}

Esta seção apresenta as dificuldades da conceitualização da expressão hospitalidade. Essas dificuldades podem ser inferidas como o produto de um efeito da complexidade inerente às atividades que a hospitalidade implica. Um distanciamento mínimo, entre atividades e significados distintos, permite uma interrogação subsidiária e condutora: a hospitalidade é mesmo complexa?

Para explorar este o foco em diferentes perspectivas e áreas de conhecimento, as palavras de Alain Montandon, teórico e organizador do volumoso livro O livro da hospitalidade - acolhida do estrangeiro na história e nas culturas, surge como uma fala oportuna. As contribuições de Montandon são frequentemente utilizadas na pesquisa teórica do âmbito do turismo e, na introdução do livro, ele afirma:

Nada é menos simples do que a hospitalidade, cujas origens etimológicas lembram que ela está ligada a noções de poder e de igualização. Nem cômodo nem espontâneo, o gesto de hospitalidade para com o estrangeiro de passagem transforma a hostilidade latente de um elemento exterior numa acolhida benévola, afável, amena, cortês.

A ambiguidade da hospitalidade aparece na língua francesa pelo fato de que a palavra hôte significa ao mesmo tempo aquele que é recebido e aquele que acolhe, sem falar do estranho parentesco etimológico que existiria entre hospes e hostis, o "hóspede" e o "inimigo". É que sempre existe temor e tensão diante do estrangeiro, quer se trate daquele que recebe ou daquele que é recebido. $O$ primeiro, diante do desconhecido que bate à sua porta, se pergunta se ele é amigo ou inimigo, vagabundo desamparado ou malfeitor animado por más intenções. Do outro lado, o viajante não sabe como será recebido, [...] (MONTANDON, 2011, p.41).

Nas diferentes especificações nesta ambiguidade da hospitalidade, dois estatutos estão envolvidos: o do hospedeiro e aquele do viajante. Por parte do hospedeiro, ele não sabe se quem chega, "é amigo ou inimigo"; por parte do viajante, ele não sabe "não sabe como será recebido". A partir destes dois estatutos iniciais e diferentes, se bifurca uma gama possível de outras compreensões sobre a hospitalidade, uma gama de diferentes significados. Nisto é possível dizer que as atividades implicadas na hospitalidade revelam a possibilidade de atitudes distintas. Em outras palavras, a expressão "hospitalidade" adquire diferentes significados conforme as diferentes atitudes humanas envolvidas.

Esta ambiguidade conferida aos significados da hospitalidade é consoante a uma apropriação fácil em seu uso. A apropriação fácil de diferentes significados e o uso ingênuo tornam cada vez mais nebulosa a atitude semanticamente implicada na atividade da hospitalidade. Exemplos desta apropriação fácil geralmente são encontrados no âmbito comercial. Neste contexto,

\footnotetext{
${ }^{1}$ Realizamos um recorte do tema da hospitalidade através dessa opção pela filosofia de Heidegger. Nesse caso, assumimos uma posição sobre o tema. Reconhecemos, contudo, que há um tratamento mais amplo proporcionado pela abordagem da hospitalidade como infinita e incondicional em Jacques Derrida. Nós optamos por esse recorte vertical, porque o nosso objetivo converte para o seguinte aspecto pontual: uma releitura dos processos conceituais e ao focar os processos, trabalhamos de uma forma mais restrita.
} 
o significado é convertido em uma prática de rotinas conforme a oferta e da procura, conforme os custos e o lucro. Mas, esta simplificação não resolve a ambiguidade da palavra, apenas a explora.

A simplificação do entendimento para a efetividade do lucro, não provê um esclarecimento da hospitalidade, mas, ao contrário, mantém o termo ainda ambíguo, adequado para um uso não qualificado. No intuito desta seção de demonstrar essa ambiguidade, destacaremos alguns exemplos de uma diversidade de significados da hospitalidade. Isto deve preparar o tratamento posterior, mais aprofundado, mediante o uso de parâmetros filosóficos.

A preocupação com a conceitualização da hospitalidade pode ser inferida na apresentação à edição brasileira do livro acima mencionado (Montandon: O livro da hospitalidade - acolhida do estrangeiro na história e nas culturas). Essa apresentação, escrita por Luiz Otávio de Lima Camargo, comenta a posição crítica de uma teórica da área: Anne Gotman a respeito do caráter "encenado" da hospitalidade. Segundo a autora, esta "encenação" existe no âmbito comercial:

Ainda como lembra Gotman em outro texto, trata-se de uma hospitalidade encenada (2008), o que redunda na constatação de que se trata de um ritual que tenta repetir o ritual ancestral da hospitalidade. Em outras palavras, as instâncias de recepção turística seriam o palco de uma encenação quase teatral de um outro ritual, que encenamos em nossa vida cotidiana: o das regras da hospitalidade que presidem nosso contato com os outros - se mais ou menos íntimos, não importa! O recepcionista num aeroporto, num hotel, seria, então, alguém que teria entre as suas atribuições encenar para os clientes o ritual codificado pela instância receptora que, por sua vez, tenta reproduzir os gestos da hospitalidade cotidiana que melhor se ajustam aos visitantes. O ritual de recepção turística guarda, pois, uma interface fundamental com a hospitalidade, ainda que como sua encenação. A dádiva é substituída pelo devido, pelo preço combinado. À diferença dos migrantes pobres, os turistas "compram" hospitalidade. O dinheiro subverte a hierarquia na cena hospitaleira. $\mathrm{O}$ cliente manda. Assim, os valores da hospitalidade ancestral pessoal e assimétrica são incorporados pela relação comercial impessoal e simétrica típica do capitalismo. A homenagem do anfitrião ao hóspede, própria da hospitalidade ancestral, é traduzida na valorização do cliente ("o cliente sempre tem razão"), a fim de levá-lo a sentir-se o centro das atenções que, ao cabo e ao fim, já estão delimitadas por padrões como produtividade, metas comerciais, etc. (CAMARGO, 2011, p.21).

$\mathrm{Na}$ descrição acima, encontramos um caso de apropriação da hospitalidade pelo âmbito comercial. O que era "ritual ancestral" se torna uma "encenação quase teatral". O que era "pessoal" e assimétrico se torna "impessoal" e simétrico. Nesta apropriação se mostra uma divisão a ser aprofundada: aqui se encontram, em contraponto, dois sistemas diferentes: o sistema da dádiva e o sistema da encenação comercial, acima descrito. O autor mostra acima que na hospitalidade encenada pelo capitalismo, o "cliente", e não exatamente o hóspede, é colocado como o "centro das atenções", gerando, inclusive planejamentos estratégicos e as preocupações com os custos e os lucros $^{2}$. Mas, sobre o sistema da dádiva, por enquanto, nada é dito. Sobre isto apenas é dado um

\footnotetext{
${ }^{2}$ Nesse sentido, um estudo de Norma Ernestina Klein Gonzàlez, na área do turismo, mostra que a aplicação de uma perspectiva quantitativa e administrativa, imiscui-se uma acepção comercial ao turismo comercial. Essa vinculação entre hospitalidade e turismo é reconhecida pelos teóricos da área: "O conceito de turismo está diretamente fundamentado no de hospitalidade". (GONZÀLEZ, 2001, p.92). Além disso, a própria OMT (Organização Mundial do Turismo) enfatiza a verificação de dados quantitativos, favorecendo a postura "administrava" do fenômeno turístico, ver Gomes et al. (2008, p.62).
} 
sinal: o sistema da dádiva seria um sistema "pessoal" e assimétrico entre o hospedeiro e o viajante. O resultado é a consolidação da ambiguidade de significados da própria palavra, e o encobrimento, ou uma premeditada ignorância a respeito das dificuldades de sua conceitualização. Mas, essas dificuldades vão repercutir quando for necessário fazer um uso teórico do conceito em uma investigação científica ou acadêmica. Ou seja, o universo de dificuldades situa-se na área acadêmica e não na atividade da área comercial. Na área comercial apenas o problema, não visto e não analisado, tende a se manter apenas potencialmente problemático, mas permanece inócuo.

Mas, por outro lado, que seja uma apropriação e encenação, o que estará sendo encenado é sempre o sistema de dádivas e não a desorganizada ambiguidade semântica do conceito. Isto insere uma esperança, pois os elementos de uma compreensão genuína da hospitalidade são sinalizados pela existência da encenação. Há sempre uma retomada potencial do sistema de dádivas em cada uma destas encenações comerciais. Mas, como é uma encenação, a retomada nunca é satisfatória e completa. Para explicitar mais, seria necessário abordar um pouco o próprio sistema: o sistema de dádivas.

O interessante é que o sistema mesmo remete a outro elemento catalizador. Ou seja, ele não se subsume ao âmbito comercial, pois "o cliente" não é o centro. No sistema de dádivas reside uma originalidade que difere fundamentalmente da impessoalidade do comércio. O comércio se beneficia da ambiguidade de compreensão e significado e a explora através de artifícios.

Camargo menciona Anne Gotman, a respeito da necessidade dos serviços de hotelaria oferecerem algo especial. Isto seria oferecido sob a forma de uma prestação de serviços personalizada. Assim, uma impessoalidade total seria impossível e o sistema de dádivas se mostra como algo que retorna, mesmo em sua forma não genuína. Há uma dependência da parte da hospitalidade encenada ou não genuína frente ao caráter mais próprio da hospitalidade. Eis as palavras de Camargo:

De qualquer forma, a conclusão de Gotman consolida a ideia de uma dupla noção de hospitalidade: a genuína, estruturada no sistema da dádiva, típica da hospitalidade doméstica e de certos setores da hospitalidade urbana, e de uma hospitalidade encenada, que pode ser adequada, mas também chegar ao fake, à caricatura, com toda a pejoratividade sugerida pelos termos, como bem ilustra a recepção havaiana em resorts de diferentes países. (CAMARGO, 2011, p.24).

Portanto, na efetividade do mundo comercial, a expressão "hospitalidade" assume diversas manifestações que se assemelham em contraponto a uma forma mais genuína. Basicamente, isto constitui um eixo que possui dois extremos: a forma genuína: "estruturada no sistema de dádivas" e sob a forma encenada ou "fake". A forma genuína remete ao papel do anfitrião e se manifesta no modo doméstico ou urbano. Ela é pessoal e assimétrica. A forma encenada procura se enquadrar dentro da forma genuína, mas resulta em uma dependência, remete à caricatura, a um uso fake do "sistema de dádiva". Ela é impessoal e simétrica, nivelada pelo pagamento em dinheiro. O que vincula ambas as extremidades deste eixo são as duas formas da dádiva. E, ao longo de todo eixo, afirma-se que tal atividade é a "hospitalidade", estabelecendo assim a ambiguidade da palavra. 
No duplo eixo da dádiva (genuíno e não genuíno), a diferença não é perfeitamente clara. Há sempre uma situação de afastamento e de proximidade entre os extremos da dádiva. Além disso, os desdobramentos concretos podem ser bem diferentes entre si: desde uma simples hospedagem oferecida a amigos, ou desde uma sofisticada hospedagem em um hotel de luxo. A nebulosa imbricação das dádivas, no âmbito concreta das atividades, pode ser vista nesta passagem de Camargo:

Mais uma vez, deve-se lembrar que um jantar que alguém oferece em casa a amigos seria uma hospitalidade genuína, ainda que possa ser marcada por eventuais gestos de hospitalidade encenada e mesmo fake, enquanto o hotel seria o palco dessa hospitalidade encenada, às vezes fake, mas com eventuais gestos da hospitalidade genuína.

Tudo se passa, assim, como se, no momento em que a hospitalidade comercial assumiu parcela da responsabilidade com o cuidado a estranhos, a presença do dinheiro instituísse o sistema do negócio e expulsasse pela porta a dádiva da hospitalidade que acaba por voltar pela janela... continuando, portanto, a existir. (CAMARGO, 2011, p.24) .

O resultado dessas considerações é o seguinte: há uma dificuldade de encontrar a clareza conceitual para subsidiar um trabalho que utilize ou parta do conceito de hospitalidade. Mas, a exploração dessas dificuldades pode abrir uma discussão sobre o processo conceitual em geral. De alguma forma, a ambiguidade referente à dimensão concreta ou efetiva do mundo, implicado na atividade da hospitalidade, encaminha a uma discussão sobre o que é um conceito e o que é fazer conceitos, ou simplesmente sobre o processo conceitual.

Diante da forma genuína e não genuína, a nossa pergunta principal se modifica um pouco e se expressa agora assim: quais são as exigências do processo conceitual quando estamos perante um uso do conceito de hospitalidade? Esta pergunta procura uma resposta que investigue a relação entre os conteúdos do processo conceitual em geral e a atividade humana em suas complexas características vinculadas ao mundo concreto. Sobre esse aprofundamento possível, selecionamos em (a) e (b) duas abordagens possíveis:

(a) Na via rigorosamente conceitual encontramos o problema do remetimento direto ao conteúdo do conceito no seu modo mais concreto. Pois, quando afirmamos que hospitalidade é um determinado objeto, estamos também referindo aos seus conteúdos (sejam eles um ato, um acontecimento, uma qualidade, um lugar etc). Nesse caso, a cada escolha de um conteúdo concreto determinado, se destaca apenas uma parte, a parte concreta, e é partir dela que se alcança o todo. A "hospitalidade" se torna bastante dependente da parte destacada. O resultado é que o processo se torna unilateralmente direto e impreciso, pois não há garantias de que tal nota característica será novamente escolhida ou selecionada como a parte que expressará o todo. Isto é particularmente problemático no caso da expressão "hospitalidade", pois, como vimos nas citações anteriores, não

\footnotetext{
${ }^{3}$ Camargo em um artigo intitulado: "Hospitalidade sem sacrifício? O caso do receptivo turístico”, de 2006, já expressava essa opinião, ver p.18-19.
} 
há um consenso sobre o que ela significa, assim esta falta de consenso é alimentada pela diversidade de exemplos provindos do mundo concreto.

(b) Em uma via não rigorosamente conceitual, extrapolando as noções de intensão e extensão e, por isto, a de notas características, encontramos a hospitalidade já como parte efetiva de um todo. Um "todo" que se propõe diverso e complexo, assumindo toda imprecisão a ser constantemente resgatada. Isto significa que a hospitalidade, não se esvazia em uma só das suas notas características. Trata-se de uma forma horizontal de compreensão do conceito, onde a verticalização de destaque de uma só parte do conceito está barrada. Esta abordagem sugere que a hospitalidade pode revelar, também, a necessidade de compreender os conceitos filosóficos de uma forma diferenciada, preservando o mundo concreto. A possibilidade desta abordagem interessa ao escopo deste artigo.

Para uma leitura das alíneas (a) e (b) procuraremos uma sustentação teórica. É certo que em alguns momentos, a filosofia se debruça sobre a sua própria prática e proporciona algumas análises sobre o processo conceitual. Temos que fazer um recorte aqui e escolhemos como foco a filosofia de Husserl. A obra de Husserl possui uma pretensão e uma envergadura muito maior do que as preocupações deste artigo, por causa disso, a nossa utilização dos seus recursos será limitada. 0 nosso objetivo é mostrar com algum parâmetro filosófico o estudo detido dos conceitos em geral. Esta tentativa faz parte de um ensejo de esclarecer a posição da hospitalidade enquanto conceito e talvez oferecer uma nova abordagem, ou pelo menos explicar as suas dificuldades conceituais.

A partir da obra de Husserl, Carlos Alberto Ribeiro de Moura, em um acurado comentário no livro Crítica da razão na fenomenologia (1989), expõe os problemas inerentes aos conceitos e aprofunda o papel das notas características (Moura denomina de "marcas características"). O autor destaca o conceito "próprio" e o conceito "simbólico", ele explora uma diferença que acompanha o que é comum tanto ao conceito quanto ao signo. Isto é feito passo a passo, vejamos o processo, iniciando pelo conceito próprio:

Um signo conceitual designa, sempre, uma propriedade intrínseca de um conteúdo, servindo como signo desse próprio conteúdo. Essa propriedade ou marca distintiva pode ser de dois tipos. Por um lado, as marcas distintivas podem ser internas, quando elas são "determinações que estão incluídas enquanto conteúdos parciais na representação do conteúdo designado" (PA, 342 4 ). Por outro lado, essas marcas distintivas podem ser externas, quando elas "são determinações relativas que caracterizam o conteúdo como um dos fundamentos de certas relações que repousam sobre ele" (PA, 342). Um conceito "próprio" é formado por marcas distintivas internas, quer dizer, por conteúdos do próprio objeto designado. Nesse sentido, Husserl pode dizer que o conceito é um abstrato, isto é, um conteúdo formado por marcas distintivas que são não-independentes em relação a um todo, que não é senão o objeto do conceito. O conceito é constituído de partes que, sendo nãoindependentes em relação ao objeto, reenviam a esse com necessidade de essência. No caso dos conceitos "próprios", portanto, existe não apenas uma afinidade de natureza entre o conceito e seu objeto, como uma conexão inevitável poderá dar-me sempre uma informação sobre o objeto. (MOURA, 1989, p.54-55).

\footnotetext{
${ }^{4}$ Moura, faz a uma citação direta à obra de Husserl com a designação (PA), trata-se do volume Philosophie der Arithmetik. Haag: Martinus Nijhoff, Husserliana, Bd. XI, 1966. Esse registro serve para as citações seguintes que se estendem no comentário de Moura, surgirá nas citações a mesma referência seguido do número de página.
} 
A passagem acima mostra como são importantes as notas características (ou "marcas distintivas") dos conceitos e que elas podem ser internas ou externas em função do conteúdo que o próprio conceito designa. Na passagem, destacamos a relação interna. Para destacar esta relação interna é importante ter em vista a diferenças entre relações internas e externas. Esta diferença se expressa em ser independente ou não ser independente frente ao conteúdo que designam: quando as relações são internas, as notas características são não-independentes em relação ao conceito como um todo, ou ao que ele designa, ou ainda, ao seu objeto. Quando as relações são externas, elas são independentes ao conteúdo designado.

Portanto, a diferença repousa entre a não-independência e a independência das notas características em relação ao "todo" do conceito, é, precisamente, o conteúdo que o conceito designa ou o seu objeto. Há uma outra relação possível: entre os signos e o "todo" dos conceitos. Trata-se agora do conceito "simbólico". Este conceito é particularmente importante porque estabelece uma diferenciação adicional mais complexa. O "conceito simbólico" é um desenvolvimento do aspecto externo e independente:

O conceito simbólico, por seu lado, ainda mantém uma relação necessária com o objeto designado, como também o caracteriza. O conceito simbólico não é formado por marcas distintivas internas, mas pelas externas; as relações que designam essas marcas distintivas, se não são partes do objeto, como no caso das marcas distintivas internas, são ainda determinações exclusivas desse objeto (PA, 194). Desde então, a relação do conceito ao objeto também será necessária e o conceito simbólico ainda me informará sobre o objeto ao qual ele remete. (MOURA, 1989, p.55).

O conceito simbólico assinala que uma "relação do conceito ao objeto também será necessária" (citação supra) e, este conceito mantém sua respectiva função, pois "o conceito simbólico ainda me informará sobre o objeto ao qual remete" (citação supra). Esta passagem citada é esclarecida pela adição de mais uma etapa que é a caracterização de signos como "signos puros", os quais são signos que deixam de ser "signos conceituais" e passam a ser apenas "signos exteriores" em um desenvolvimento dos signos simbólicos. Essa forma pura do signo estabelece a possibilidade de uma relativa arbitrariedade frente ao que é designado conforme se vê na seqüência do parágrafo já citado:

Ora, são exatamente esses dois fatores que desaparecerão, quando, em uma simbolização de terceiro grau, chegarmos aos puros signos. Agora, é essa relação essencial que desaparecerá, e o signo por si mesmo não informará nada sobre o designado. No terceiro grau da simbolização, saímos do domínio dos "signos conceituais" para aquele dos "signos exteriores", quer dizer, para o domínio dos signos que Husserl define como os que mantêm uma relação puramente arbitrária com seu designado, que não têm nada a ver com o conteúdo nem com as propriedades do objeto, e que portanto apenas o designam, sem o caracterizarem (PA, 314-2). (MOURA, 1989, p.55).

Retornando à discussão sobre hospitalidade, percebe-se que o seu conceito encontra esses mesmos efeitos. Ou seja, gradativamente aumenta a distancia entre signo e o conteúdo. Em função dessa distância, podemos dizer que o uso da expressão, enquanto conceito (no caso da "hospitalidade") acaba sendo relegado a uma "relação puramente arbitrária com o seu designado". Se esta distância é mantida, subsiste uma ambiguidade na duplicidade dos desdobramentos do sistema de dádiva que envolve a forma genuína e a forma não genuína ou comercial. 
A arbitrariedade dos signos exteriores em relação ao designado assinala dois aspectos importantes: a não-propriedade e a independência dos signos frente ao conteúdo designado. Esses aspectos mostram a centralidade da relação entre signo e o objeto mesmo dos conceitos. Contudo, em um grau mais amplo nas relações entre signo e conceito, o conceito simbólico é significativamente diferente do conceito próprio. E, esta é uma via ser explorada.

Finalmente, a apresentação dos parâmetros filosóficos sobre o conceito próprio e o conceito simbólico, inspirado em Husserl, lançam luz sobre a análise conceitual da hospitalidade. $\mathrm{Na}$ passagem citada, já identificamos duas vias: (a) a via conceitual e (b) a via não conceitual. Agora, podemos retomar esse procedimento sob uma reidentificação mais específica: a alínea (a) conforma-se ao conceito próprio; e a alínea (b) conforma-se ao conceito simbólico, tornando-a de alguma forma, também uma via conceitual, mas uma via conceitual diferenciada. Detalharemos esta reidentificação agora com o tema da hospitalidade. Assim, consideraremos (a) reidentificada como (a-1) e (b) reidentificada como (b-1). Ambas são explicitadas abaixo:

(a-1) O conceito próprio, em relação à hospitalidade, não pode ser a forma mais adequada para um tratamento teórico. Pois, nas notas características do conteúdo de hospitalidade não há um remetimento interno e não-independente ao "todo" do conceito. Isso significa que as suas notas características são diversas e que podem impedir e, de fato, impedem um "fechamento" conceitual. Essas notas não possuem um remetimento não-independente, portanto dependem do conteúdo designado. Mas, há uma indeterminação no comportamento humano que impossibilita um uso adequado desta forma "própria" do conceito. Se essa posição é aceitável, então a via da letra (a) deve ser descartada e, consequentemente, também esta (a-1).

(b-1) Em relação à hospitalidade, a forma simbólica do conceito parece mais adequada. Nela temos a característica do remetimento externo e arbitrário das notas características ao conteúdo designado pelo conceito. Essa externalidade apela ao uso de signos. $E$, eles não remetem necessariamente à hospitalidade. Trata-se de uma característica dos signos: eles são independentes do conteúdo que venham a designar, a vinculação não é necessária. Há, certamente, uma participação da indeterminação do comportamento humano no conteúdo externo/arbitrário referido pelos signos, isto é uma descrição ampla do uso humano dos signos. Se isso é plausível, então são os aspectos mais próprios da existência humana que colaboram para a dificuldade de se conceitualizar a hospitalidade. Esta indeterminação é realçada quando se devem conceber conceitos difíceis como a hospitalidade. A consequência é a de que o processo conceitual deve ser revisto. É o que faremos mais adiante utilizando os indícios-formais elaborados por Heidegger.

A relação entre as alíneas (b) e (b-1) mostra outro tipo enfrentamento do problema de conceituar expressões complexas e ambíguas como a hospitalidade. A via do conceito simbólico permite uma leitura que pode implicar diretamente os modos de ser da existência humana. Se este é o caso, então a compreensão do que é a hospitalidade ultrapassará mesmo as exigências formais de um processo conceitual mais ortodoxo, ou um processo inserido e aceito na tradição. Podemos a partir disso, formular a hipótese de que esta indeterminação, causadora da dificuldade, se deve simplesmente à própria existência humana. Se essa hipótese é correta, então se justifica conjecturar sobre uma modificação na forma de conceber os conceitos filosóficos, procurando responder de modo mais adequado à conceituação de atitudes diretamente relacionadas com o ser humano. 
A nossa investigação assume assim um novo direcionamento aberto pela hipótese recémenunciada. Ou seja, a hospitalidade precisaria de uma nova forma conceitual que deve ser mais propícia para expressar os diferentes modos da existência. Nessa direção, certamente se inscreve há uma consequência geral sobre o trabalho conceitual da filosofia. Mas, isto deve ser uma consequência de um tratamento alternativo que ainda será mostrado. Para explorar esta hipótese veremos alguns tópicos da filosofia de Heidegger dentro de uma proposta de rever os conceitos filosóficos por meio dos indícios-formais da existência.

\section{UM APROFUNDAMENTO NO USO DOS CONCEITOS E A AS ATITUDES HUMANAS}

A filosofia de Heidegger no início da década de 20 (século passado) se identifica com a fenomenologia de Husserl, mas gradativamente acentua outras origens e assume caminhos próprios. Além de Husserl, Heidegger sofreu outras influências determinantes como a da teologia dos primeiros cristãos, do neokantismo e da hermenêutica de Dilthey. Seguir um caminho fenomenológico diferente de Husserl representa uma tomada de posição por parte de Heidegger ${ }^{5}$. Ele retira da fenomenologia algumas intuições metodológicas importantes, as quais contribuem para descrever a hermenêutica da vida fática. Esta descrição é parte de seus objetivos nos anos 20.

Na passagem abaixo das aulas do semestre de inverno de 1920-1921, encontramos alguns aspectos que mostram a singularidade do posicionamento de Heidegger. 0 título deste curso é fenomenologia da vida religiosa e a passagem versa o seguinte:

A classificação do ente pode ser vista como uma consideração ontológica. Enquanto ente, sendo tal para uma consciência, a classificação ontológica responde a uma consciência relativa na qual se pergunta pela conexão das "formas de consciência" nas quais o ente "se constitui", quer dizer, se torna consciente. Este problema foi colocado por Kant; porém a fenomenologia (de Husserl) foi a primeira a ter os meios para levar este estudo concretamente a cabo. Pelo lado ontológico, a filosofia necessita ocupar-se com o ente; pelo lado da consciência, com as leis originárias da constituição da consciência. Tudo quanto é objetualidade jaz sob a forma desta constituição. Na fenomenologia de Husserl, a consciência transforma-se numa região e sujeita-se a uma consideração regional. Sua normatividade não é apenas em princípio a mais originária, mas também a mais geral. Ela se expressa em geral originariamente na fenomenologia transcendental. (HEIDEGGER, 2010, p.53).

Esta referência ao ente integra o eixo principal da sua investigação, a qual será expressa em outro momento como a relação entre o ser e o ente. Este eixo se insere dentro do âmbito da ontologia, melhor dito, dentro de uma preocupação sobre a gênese ontológica ${ }^{6}$. Contudo, é

\footnotetext{
${ }^{5}$ Para um aprofundamento sobre a existência de uma diferença entre a filosofia Heidegger do início dos anos 20 , centrada na hermenêutica da faticidade; e a ontologia existencial de Ser e tempo, veja-se o questionamento de L. Hebeche: "Mas até que ponto uma "ontologia" não é uma teoria? A resposta de Heidegger é que a ontologia existencial antecipa-se a toda teoria, o que não quer dizer que caia no irracionalismo. No entanto, a dívida para com o método da fenomenologia não pode ser saldada facilmente. Essa é a dificuldade filosófica que o jovem Heidegger procurou resolver, [...]." (2001, p.581-582).

${ }^{6}$ Para uma perspectiva sobre a vinculação entre hermenêutica da faticidade e a ontologia fundamental de Ser e tempo veja-se Róbson Reis, 2000, p.273-300, especialmente o uso da expressão: "gênese ontológica", na p.277 e na nota 15.
} 
importante destacar aqui que a área da ontologia é transpassada pela hermenêutica e pela faticidade da existência. Dessa forma não se trata mais de uma ontologia com matizes dogmáticos como as que existiram no século XVII e XVIII, ou mesmo de uma forma derivada do idealismo alemão.

Os tópicos mais importantes da passagem citada acima são o uso do conceito "consciência" e a diferença colocada por Heidegger frente à Husserl. Para compreendermos o que está subjacente a estes dois tópicos é preciso assinalar que Heidegger divide entre o que é originário e o que não pode ser originário. Aquilo que não é originário é derivado. Assim, em uma "consideração ontológica", o tema da consciência, abordado por Husserl, pode ser importante, mas não é originário. Segundo Heidegger, antes da consciência se apresentaria o ente em sua faticidade. A classificação entre originário e derivado direciona o posicionamento de Heidegger frente à Husserl e, também, frente à tradição filosófica.

Na passagem acima, podemos delinear uma posição de Heidegger não só sobre Husserl, mas, a respeito também de Kant, quando Heidegger afirma que este problematizou a "conexão das 'formas de consciência'" e ponderou o alcance fundamental dessa conexão para o ente que conhece, ou "se torna consciente". Em razão disso, Kant voltou-se ao ente, mas se deteve nos juízos do entendimento a toda experiência possível. O foco de Kant não encetou a "consideração ontológica" a respeito do ente. E, Husserl, de forma derivada e não originária, segundo Heidegger, buscou esclarecer as "leis originárias da constituição da consciência", transformando, assim, a consciência "em uma região" sujeita "a uma consideração regional". Finalmente, Heidegger conclui que, ambos os filósofos, estão enraizados na subjetividade, preocupados com o tema do conhecimento. Diante dessa preferência, a "consideração do ente" ficaria deslocada, sem uma tematização.

A passagem citada termina mencionando que o caminho de Husserl, ao fundar uma fenomenologia transcendental, se comprometeu ainda mais com o esclarecimento dos fundamentos da subjetividade. Esta separação em relação à Husserl, por parte de Heidegger, pode ser percebida na preocupação a respeito da "consideração sobre o ente", a qual ele vinculará à faticidade do ente que é existente (o ser-aí), finalmente, que somos nós, cada um de nós.

No âmbito da faticidade se realizaria uma "consideração do ente". O que é isso? Pois, qualquer tipo de consideração, mesmo a "consideração do ente" é feita por meio de conteúdos temáticos? Mas, Heidegger se afasta da tradição conceitual filosófica? A resposta é que esses conteúdos dizem respeito diretamente à vida fática, aos seus fenômenos e não a uma "consideração regional" centrada na consciência e, por isto, não na tradição sob forma da subjetividade. No foco vinculado à vida fática, a "objetualidade" dos conteúdos temáticos precisa ser apresentada diferentemente no processo usual de "formular" os conceitos filosóficos. Esta necessidade de uma diferenciação modifica a forma de compreender os conceitos filosóficos. Surge, então, um tipo especial de conceitos: os indícios-formais.

Algumas páginas após a passagem citada acima, Heidegger aprofunda a base existente no signo ou na palavra que constitui ou expressa um conceito. Na interpretação de Heidegger, essa base remete à atitude humana e não a uma mera predicação: 
A predicação formal não está tematicamente ligada, contudo deve estar de algum modo motivada. Como está ela motivada? Brota do sentido da referência atitudinal mesma. Eu não retiro pelo olhar a quididade que determina a coisa a partir da objetualidade, mas vejo sua determinação como estando conscientemente "nela". É necessário afastar o olhar de sua quididade e ficar atento para que a objetualidade seja dada e captada atitudinalmente. É desse modo que a formalização surge do sentido referencial da pura referência atitudinal mesma e não de uma "quididade" geral. (HEIDEGGER, 2010, p.54-55).

O afastamento de um procedimento que visa apenas uma "'quididade' geral" (a essência enquanto forma pura) mostra a diferença entre a proposta de Heidegger e a ontologia clássica ou, ainda, frente a outras neo-ontologias. Não se trata, na filosofia de Heidegger, de buscar a "quididade", mas sim de tematizar a hermenêutica da vida fática7. E, é por isto, que nessa hermenêutica que se destacará a "referência atitudinal" ou, em outras palavras, se buscará expressar as diferentes manifestações da existênciå. Entre estas manifestações está a hospitalidade com suas dificuldades conceituais.

O problema aqui são os conteúdos de expressões complexas a exemplo da expressão hospitalidade 9 . Todo conceito visa a uma "objetualidade", na qual se constitui uma compreensão (intensão com "s") e uma extensão. Mas, no caso da hospitalidade, o conceito se torna peculiar porque a objetualidade que ele gera compreende-se como "dada e captada atitudinalmente". O recurso filosófico de apresentar este tipo peculiar de captação do conteúdo do conceito é uma das grandes contribuições metodológicas de Heidegger e é um eixo que subjaz ao texto de Ser e tempo.

Esse é outro modo de se conceber os conceitos. Um novo recurso que depende de uma reconfiguração do filosofar, assumindo como vetor principal a existência humana (a "referência atitudinal). Aqui se destacam as dificuldades de todo uso meramente formal (no caso: uso da predicação) com a usual composição do entendimento das notas características e a extensão de um conceito. Esse processo formal não consegue dar conta da riqueza efetiva abarcada pela palavra "hospitalidade", provocando sempre uma oscilação ou uma ambiguidade.

Mas, esta incapacidade formal é reversível mediante um processo hermenêutico existencial ou fático. É neste aspecto, ao valorizar as manifestações da existência, que se insere a contribuição

\footnotetext{
${ }^{7}$ Nos referimos aqui principalmente as obras do início dos anos 20 do século passado, onde o tema da hermenêutica da faticidade surgiu e predominou até a ontologia fundamental de Ser e tempo (1927) começar a ser trabalhada. Por este motivo, os textos-base desse artigo são os volumes dos semestres de inverno 1920/21 (GA. 60) e de 1921/22 (GA.61) nas passagens sobre indícios-formais e a vida fática. Uma discussão sobre a continuidade ou ruptura ao longo do desenvolvimento heideggeriano, a respeito da hermenêutica da faticidade e da ontologia fundamental, necessitaria um trabalho a parte.

${ }^{8}$ Ver Róbson Reis: “O contexto atual examinado por Heidegger a título de exemplo envolve noções centrais da analítica da existência humana: morte, decisão antecipadora, autenticidade e inautenticidade, existência e história. Os conceitos elaborados para apresentar esse contexto temático são compreensíveis, caso não sejam tomados como expressando propriedades e referindo-se a determinações de um ente subsistente. Eles indicam a requisição de uma compreensão ativa que se oriente para os recursos hermenêuticos de que dispõe o intérprete: a compreensão deve se desvencilhar de conceitos ontológicos homogeneizados" (2004, p.174).

${ }^{9}$ Outros exemplos de expressões complexas que são de difícil conceitualização são: história, morte, etc.
} 
heideggeriana dos indícios-formais. Vamos aprofundar este tema para prover um direcionamento metodológico possível que vise ao tema da hospitalidade ${ }^{10}$.

O ponto de partida para um aprofundamento pode ser a pergunta: quais são as bases que Heidegger utiliza para contrapor a preocupação de Husserl com a constituição da consciência? $\mathrm{Na}$ passagem mais acima, essas bases convergem para as motivações existentes nas predicações ou no ato de predicar. Isto sinaliza que não é a predicação (sob o modo ortodoxo de elaboração de conceitos filosóficos), mas sim o que está colocado antes de toda predicação que é o determinante. Tais motivações, impensadas em Husserl, remetem às atitudes humanas. $E$, coerente com isso, a "objetualidade", nas palavras de Heidegger remeteria à "pura referência atitudinal", ou seja, à existência.

Neste mesmo volume sobre Fenomenologia da vida religiosa, na parte intitulada "Introdução à fenomenologia da religião", Heidegger explicita a "referência atitudinal" como uma outra forma de encaminhamento do próprio filosofar ${ }^{11}$. Aqui se percebe a radicalidade de sua proposta. Pois, não ela somente expressa a filosofia diferentemente da tradição, mas também a necessidade de que esta diferença seja executada. Um dos pontos principais é o de que o aspecto "formal" de um conceito depende de uma "realização originária". Esta "realização originária" expressa as atitudes humanas, ou seja, vincula-se à existência:

Somente assim as determinações referenciais podem ser vistas a partir das atitudes. A referência atitudinal pura deve ser contemplada ainda como realização para entender a origem do teórico. Porém, o filosofar deve ser considerado em sua realização atitudinal originária, como veremos mais tarde; então se aclarará também a relação entre a explicação fenomenológica e o comportamento intelectivo. A origem do formal radica, portanto, no sentido referencial. Aquela pluralidade de sentidos referenciais que se expressa nas categorias ontológico-formais é a que circunscreve em seu sentido referencial a atitude teórico-própria, se bem que em sua realização originária. (HEIDEGGER, 2010, p.55).

O que é denominado de "realização originária" é que permite o surgimento de uma "atitude teórico-própria" como desenvolvimento da "realização atitudinal". Em relação a "realização

\footnotetext{
${ }^{10}$ Francisco de Lara aponta três dificuldades acarretadas no modo de ser da linguagem durante processo de tematização em geral. Essas dificuldades são classificadas como ilusões. Assim temos a ilusão de proximidade, em função do discurso científico que se pretende mais próximo das coisas; a ilusão ontológica, onde dominam o uso de categorias como substância e objeto; e a ilusão analítica, onde a divisão das partes da linguagem conduz a ilusão de as relações e articulações entre as partes nos fornecem as coisas. De Lara completa: "Por ello considera que el lenguaje filosófico solo puede cumplir su particular función metódica si es tal que, teniendo en cuenta las dificultades mencionadas, actúa indicando formalmente aquello que pretende poner de relieve. La indicación formal funcionaría como un recurso fenomenológico en ese sentido, impidiendo que la tematización originaria deje de ser tal. La posibilidad de mantenerse en una tematización guiada originariamente por la concreta experiencia de aquello de lo que hace cuestión es algo que debe ser mantenido y salvaguardado todo el tiempo, desde el inicio y la puesta en marcha de la investigación, sobre todo, hasta la comunicación a otros de la misma." (2012, p.26) A tematização da hospitalidade enquanto um indícioformal deve ser visualizada a partir do vivido, enfrentando as dificuldades que se apresentarem.

${ }^{11}$ Heidegger reforça a importância de conceber o filosofar de um modo diferente da tradição e dos seus problemas que são legados. Heidegger concebe um outro modo da filosofia perante tais problemas provindos da tradição filosófica: "Ao contrário, e isto repousa no sentido da definição indicativo-formal da filosofia, tanto é apropriada mais propriamente no sentido fundamental da situação fática do comportar-se, quanto mais originário e autêntico realizase o esclarecimento do sentido indicativo-formal da filosofia". (1994, p.62).
} 
atitudinal", se ela é considerada como "originária", então ela é também considerada uma manifestação do filosofar. Trata-se aqui de um movimento para compreender: as "determinações referenciais", a "origem do teórico" e o "comportamento intelectivo" de um modo diferente do filosofar tradicional. O ponto principal é aquele desempenhado pela atitude, a qual está inserida na definição do processo filosófico e que deriva (ou se desenvolve) em um processo teórico. A forma tradicional da filosofia encontra muitos problemas para conformar estes tipos de conteúdos temáticos e suas objetualidades, quando se confronta com a existência humana. Isto ocorre, por exemplo, com os conteúdos temáticos da hospitalidade. Tal como vimos na primeira seção deste artigo.

Em contrapartida, a valorização da atitude, colocada antes do próprio fazer teórico, ela se apresenta como uma possibilidade de compreender a origem deste fazer teórico. Se a atitude e, nisso, a existência, surgem por meio desta outra perspectiva, então o teórico se tornaria dependente de algo mais originário. $\mathrm{O}$ caráter originário do teórico estaria enraizado na existência humana.

Um consequência imediata no processo de formalização do fazer teórico é que ele se torna passível de uma releitura a partir do elemento mais originário: a existência. Explorar essa consequência significa preparar uma modificação no modo de se conceber a prática do próprio filosofar. Essa indicação está implícita na frase de Heidegger: "o filosofar deve ser considerado em sua realização atitudinal originária"12.

Portanto, em alguns casos de conceituações problemáticas ou complexas, como por exemplo, no caso da hospitalidade, podemos ter esta outra forma de conceber os conceitos filosóficos. Essa forma permitirá tematizar a partir das manifestações da atitude humana. Assim sendo, é preciso investigar estes detalhes de qual é este outro "formal"13. É, neste ponto é que utilizamos o recurso heideggeriano dos indícios-formais.

Com o intuito de justificar essa alternativa, realizaremos um confronto entre os indíciosformais e os conceitos filosóficos tradicionais: os indícios-formais servem como um alerta a uma

\footnotetext{
12 Em 1929/30, Heidegger, já em um período além da hermenêutica da faticidade do início dos anos 20, vai radicalizar esse discurso, ao falar sobre os indícios-formais como conceitos, os quais requisitam do Dasein (ser-aí) uma transformação: "Toda conexão entre existência autêntica e inautêntica, instante e ausência de instante não diz respeito a algo simplesmente dado que se passa com o homem, mas a uma conexão própria ao ser-aí. Com isto, os conceitos que a trazem à tona só são compreensíveis se não forem tomados como se designassem propriedades de um ente simplesmente dado. Ao contrário, é preciso que eles sejam tomados como indicações do fato de que a compreensão precisa primeiramente se desprender das concepções vulgares do ente e se transformar explicitamente no ser-aí neste ente. Em todos estes conceitos - morte, decisão, história, existência - reside a requisição por esta transformação; e em verdade, não como uma espécie de aplicação ética ulterior do que foi concebido, mas como uma abertura prévia da dimensão do que é concebível. Porque os conceitos, uma vez que se deixam conquistar autenticamente, só deixam sempre interpelar discursivamente esta requisição por transformação, mas nunca podem eles mesmos provocar o acontecimento da transformação, eles são indicadores. Eles apontam para o interior do ser-aí" (2003, p.338-339, itálicos do autor).

${ }^{13}$ No contexto filosófico da elaboração da hermenêutica da faticidade, Heidegger no semestre de inverso de 1921/22, no volume 61 das obras completas, afirma: “'Formal', o 'formal' é um tal conteúdo que ele remete na direção do indício, ao caminho esboçado. 'Indicando formalmente', aqui para não se dissociar na filosofia. O formal não é 'forma' e indicação de tal teor, mas sim, 'formal' é início da determinação; o caráter do início!” (1994, p.34).
} 
provável reificação da existência humana, resultado de um prejulgamento. Heidegger afirma o seguinte:

Como se pode prevenir esse prejulgamento? Para isso trabalha o indício formal. Ele pertence, como momento teórico, à explicação fenomenológica mesma. Por que é chamado de "formal"? O formal é algo relativo à referência. $O$ indício deve indicar antecipando a referência do fenômeno - num sentido negativo, porém, como se a tratasse de uma advertência! Um fenômeno deve ser dado previamente de tal modo que seu sentido referencial seja originariamente teórico. A referência e a realização do fenômeno não se determinam, de antemão, mas estão em suspensão, à espera de concretização. Esta é uma posição que opõe frontalmente à ciência. Não existe nenhuma inserção num campo temático, mas, em contrapartida, o indício formal é uma defesa, um asseguramento prévio de modo que o caráter realizador ainda permanece livre. A necessidade desta medida de precaução procede da tendência decadente da experiência fática da vida que ameaça constantemente a decair e a se desviar, extraviando-se para a objetividade e da qual, em contrapartida, precisamos evidenciar os fenômenos. (HEIDEGGER, 2010, p.58-59).

A riqueza dos indícios-formais, para expressar os mais diferentes fenômenos, que dizem respeito à existência humana, é assegurada na "suspensão", na qual o indício-formal antecipa a "referência do fenômeno". Isto significa uma ação anterior, aquela realizada pelo indício-formal antes do fechamento de uma conceituação em suas respectivas "notas características". Na suspensão, feita pelo indício-formal, o originário se destaca e aponta (ou indica) uma manifestação da existência. Isto é diferente do que está expresso no "conceito próprio", entendido husserlianamente e citado bem mais acima na primeira seção.

A riqueza metodológica dos indícios-formais é vertida para uma conceitualização alternativa, tornada disponível para palavras complexas, ambíguas e vinculadas à existência, como a hospitalidade. Nesta direção, a hospitalidade pode ser considerada como um dos indícios-formais da existência. Ela ocorre antes de um trabalho teórico e reside em uma atitude (realização atitudinal). A hospitalidade somente pode ser apresentada em um trabalho teórico, em um trabalho crítico prévio, com esta abertura de um tipo especial de conceito filosófico: os indícios-formais.

$\mathrm{Na}$ citação mais acima, Heidegger utiliza a expressão "explicação fenomenológica", vinculando esta "explicação" à existência fática. Neste movimento há dois fatores que podem ser destacados: (a) podemos sim tematizar filosoficamente a existência humana e, para tanto são necessários estes novos conceitos filosóficos originários, os quais são expressos pelos indíciosformais (onde se imiscui a hospitalidade); e (b) Heidegger marca uma posição distinta daquela de Husserl, não vinculando o seu trabalho a uma fenomenologia transcendental, mas à existência fática. Nesse sentido, pensar os conceitos filosóficos como indícios-formais significa compreender que eles "apontam" ou "indicam" uma complexidade, que é a existência. O indício-formal configura uma espécie de "defesa" do "caráter realizador" que ele acompanha, exemplificado na expressão utilizada pelo filósofo: a "realização atitudinal". A existência que o indício-formal aponta é o contrário de uma valorização da objetividade ${ }^{14}$. A existência se mostra enraizada em uma

\footnotetext{
${ }^{14}$ No semestre de 1921/22, Heidegger já se refere a esse caráter do indício-formal: "O indício-formal impede toda manobra de desvio de modo independente, isolada de pressuposição de interpretação[Interpretationsvoraussetzung], de concepção-prévia de interpretação [Interpretationsvorgriff], de conexão de interpretação HOLOS, Ano 36, v.2, e5881, 2020 
"realização atitudinal" e se expressa sob outra forma dentro do ato de filosofar ${ }^{15}$. Nesta outra forma se torna possível recuperar os fenômenos sem perder a objetualidade da referência por meio de uma determinada realização atitudinal. Entre estes fenômenos recuperados, está a hospitalidade. Ela agora é colocada em uma tematização que escapa de um processo conceitual filosófico tradicional, e se insere ainda em uma tematização teórica, mas factível.

\section{CONCLUSÃO}

A nossa investigação centrou-se nas dificuldades de conceituar a palavra hospitalidade, embora a mesma seja utilizada em meios acadêmicos e não acadêmicos. A pergunta: "como é possível conceituar a hospitalidade?" conduziu a um estudo sobre o processo conceitual em geral, tal como este é tradicionalmente definido pela filosofia por meio de uma dupla relação entre: notas características e extensão de um conceito.

A conclusão mostrou na primeira parte que a palavra hospitalidade possui, de fato, uma ambiguidade e que a forma tradicional de conceber os conceitos não consegue dirimir esta ambiguidade. A primeira parte encerra encaminhando outras formas de conceber os conceitos filosóficos, a exemplo do "conceito simbólico" de Husserl.

A segunda parte aprofunda este encaminhamento, aberto pelo "conceito simbólico", expondo a concepção heideggeriana dos indícios-formais. Ela se torna a abordagem metodológica mais adequada para expressar a existência humana. Neste sentido, a hospitalidade assinala uma das manifestações da existência humana, o que explica a dificuldade da conceituação mais tradicional.

Finalmente a resposta final mostra que o recurso aos indícios-formais, tal como os elabora Heidegger, é o modo mais indicado para tratar conceitualmente a hospitalidade. Este tratamento é propiciado pela riqueza metodológica dos indícios-formais, ao permitirem a expressão da "realização atitudinal", e permitirem um enraizamento na existência do ser humano. Sem pretensões de esgotar o assunto, esta conclusão é uma contribuição ao debate acadêmico sobre a hospitalidade e seu conceito.

\footnotetext{
\{Interpretationszusamenhang] e tempo de interpretação [Interpretationszeit], cegas fixações dogmáticas do sentido categorial na certezas do aspecto de algo sobre o seu sentido de ser em indiscutida objetividade" (1994, p.142).

15 Em Ser e tempo, portanto, anos após os cursos de 1920/21 A fenomenologia da vida religiosa e também ao semestre sobre as Interpretações fenomenológicas sobre Aristóteles (1921/22), anos do tema da hermenêutica da faticidade, Heidegger reafirma, em 1927, a vinculação dos indícios-formais com a existência, nesse caso, a partir da centralidade no Dasein (o ser-aí): “O indício-formal da idéia de existência foi guiado pela compreensão do ser que é desde o, e no Dasein em si mesmo. Apesar de faltar transparência ontológica, esta compreensão revela que o ente que nós chamamos Dasein, sou a cada vez sempre eu mesmo e, não obstante, enquanto poder-ser está em jogo o ser deste ente. O Dasein se compreende enquanto ser-no-mundo, ainda que sem uma suficiente determinação ontológica. (1977, p.415).
} 


\section{REFERÊNCIAS}

CAMARGO, L. O. de L. (2006). "Hospitalidade sem sacrifício? O caso do receptivo turístico". In: Revista Hospitalidade. São Paulo, ano III, no: 2.2 sem, p.11-28.

CAMARGO, L. O. de L. (2011). "Apresentação à edição brasileira. O estudo da hospitalidade". In: MONTANDON, Alain (dir.). O livro da hospitalidade: acolhida do estrangeiro na história e nas culturas. São Paulo: Senac.

GONZÁLEZ, N. E. K. (2002). “Hospitalidade e preconceito no turismo”. In: Turismo: Visão e Ação. Ano 4, no: 10, Out. 2001/mar, p. 91-100.

GOMES, C. L.et al. (2008). "Inserção do lazer no contexto da pós-graduação strictu sensu em turismo/Hospitalidade no Brasil”. In: Caderno Virtual de Turismo, v.8, no: 3, p.54-66.

HEIDEGGER, M. (1977). Sein und Zeit. Frankfurt am Main: Vittorio Klostermann. GA.v.2

HEIDEGGER, M. (2010). Fenomenologia da vida religiosa. Petrópolis: Vozes; Bragança Paulista: Editora Universitária São Francisco. GA. v. 60.

HEIDEGGER, M. (1994). Phänomelogische Interpretationen zu Aristoteles - Einfürung in die Phänomenologische Forschung. Frankfurt am Main: Vittorio Klostermann. GA. v. 61.

HEIDEGGER, M. (2003). Conceitos Fundamentais da Metafísica: Mundo Finitude e Solidão. Rio de Janeiro: Forense. GA. v. 29/30

HEBECHE, L. (2001). "Heidegger e os indícios-formais". In: Veritas. Porto Alegre, v.46, no:4. p.571-592.

LARA de, F. (2012). "El estatuto fenomenológico de la indicación formal em Heidegger". In: Filosofia Unisinos, 13(1), jan./abr., p.15-29.

MONTANDON, A. (2011). "Introdução". In: MONTANDON, Alain (dir.). O livro da hospitalidade: acolhida do estrangeiro na história e nas culturas. São Paulo: Senac.

MOURA de, C. A. R. (1989). Crítica da Razão na fenomenologia. São Paulo: Nova Stella, Editora da Universidade de São Paulo.

REIS, R. R. (2000). "Modalidade existencial e indicação-formal: elementos para um conceito existencial de moral". In: Natureza Humana, 2 (2). p.273-300.

REIS, R. R. (2004). "ilusão e indicação formal nos conceitos filosóficos". In: Integração. Abr./mai./jun., ano 10, no: 37, p.171-179. 